\title{
Cerebellar Atrophy in Epileptic Patients
}

\author{
M.I. Botez, Ezzedine Attig and Jean Lorrain Vézina
}

\begin{abstract}
High-resolution CT scans of the brain and posterior fossa were performed on 106 phenytoin (PHT)treated epileptics, 28 de novo epileptics and 43 control subjects. A higher incidence of cerebellar and brainstem (CBS) atrophy was observed in chronic PHT- or PHT + phenobarbital-treated epileptics compared to the two other groups. Some control subjects and de novo epileptics presented mild CBS atrophy, whereas moderate to severe atrophy was noted exclusively in chronically-treated patients. In attempting to delineate the etiology of CBS atrophy, epileptic patients were divided in three groups: 55 subjects with normal CT scans, 30 with both cerebral and CBS atrophy, and 49 with pure CBS atrophy. Their ages, length of illness, number of generalized seizures, number of other seizures, and amount of PHT received during their lifetime were assessed. Statistical analysis revealed that posterior fossa atrophy in epileptics was significantly correlated with both the length of the illness and the amount of PHT ingested during the patient's lifetime. The number of seizures appears to not be related to CBS atrophy.
\end{abstract}

RÉSUMÉ: L'atrophie cérébelleuse chez les épileptiques. On a pratiqué la tomodensitométrie du cerveau avec haute résolution pour la fosse postérieure chez 106 épileptiques chroniques traités à la phénytoine (PHT), chez 28 épileptiques chroniques traités à la PHT, chez 28 épileptiques de novo et chez 43 sujets-contrôles. Nous avons retrouvé une fréquence significativement élevée de l'atrophie cérébelleuse et du tronc cérébral (ACTC) chez les épileptiques chroniques par rapport aux deux autres groupes. Certains sujets contrôles et épileptiques de novo ont présenté une atrophie ponto-cérébelleuse légère tandis que les atrophies modérées ou sévères ont été observées en exclusivité chez les épileptiques. En essayant de préciser l'étiologie de l'ACTC, 134 patients traités sur base externe ont été divisés en trois groupes: 55 sujets avec une tomodensitométrie du cerveau normale, 30 patients avec ACTC et avec atrophies cérébrales et 49 épileptiques avec des ACTC pures. Les paramètres étudiés ont été l'âge, la durée de la maladie, le nombre de crises de grand-mal, le nombre d'autres crises et la quantité de PHT ingérée pendant la vie du malade. Les analyses statistiques ont démontré que l'ACTC est corrélée avec la durée de la maladie et avec la quantité totale de PHT ingérée pendant la vie du malade. Le nombre de crises n'était pas apparemment relié avec la fréquence de l'atrophie des formations de la fosse postérieure.

Can. J. Neurol. Sci. 1988; 15:299-303

Cerebellar atrophy has often been noted in epileptic patients, usually not in association with clinical manifestations of chronic ataxia. ${ }^{1-14}$ The role of phenytoin (PHT) in the etiology of cerebellar degeneration is a matter of controversy. In some studies, a direct toxic action of the drug has been incriminated while in others hypoxia of Purkinje cells following frequent epileptic seizures has been considered a causal factor. ${ }^{15,16}$ Histologic changes expressing cerebellar atrophy were reported by Spielmeyer ${ }^{17}$ long before the identification of PHT as a major anticonvulsant drug by Merritt and Putnam. ${ }^{18}$ Dissident opinions have been voiced by Ballenger et al ${ }^{19}$ who, in CT scans of 70 patients with seizures and 48 control subjects, found no evidence that either PHT or epilepsy causes cerebellar atrophy. The aim of the present study was to: 1. establish the frequency and severity of cerebellar atrophy in three population groups: outpatients with recent onset of seizures, chronically-treated epileptics, and normal controls; and 2. elucidate possible relationships between cerebellar and brainstem (CBS) atrophy and age, length of illness, total amount of PHT ingested during lifetime, number of generalized tonic-clonic seizures, total number of other kinds of seizures (partial, elementary or complex, with or without secondary generalization), and periods of PHT intoxication in the past.

\section{METHODS}

\section{Patients}

Our initial study was conducted on 208 subjects, comprising 144 outpatient epileptics and 64 normal controls, on whom we performed CT scans to evaluate the correlation between the subjective grading of pontocerebellar atrophy and the objective ratios of the fourth ventricle and brainstem. The epileptic group contained chronic and de novo epileptics with idiopathic primary or secondary generalized seizures. The controls with diagnoses of muscle tension headaches and low back pain, were chosen from our general neurology clinic. The purpose of this study was to specifically assess the degree of cerebellar atrophy in chronic epileptic patients as compared to de novo epileptics and controls subjects. We employed the inclusion criteria of Mattson et al 20 by selecting: (i) men and women aged 18 years

From the Neurology Service and Department of Radiology, Hôtel-Dieu de Montréal and Centre Hospitalier Rouyn-Noranda, Québec, Canada Received October 2, 1987. Accepted in final form April 25, 1988

Reprint requests to: Dr. M.I. Botez, Head, Neurology Service, Hôtel-Dieu de Montréal, 3840 St-Urbain, Montréal, Québec, Canada H2W IT8 
and over, attending epilepsy outpatient clinics; (ii) patients diagnosed as chronic or de novo epileptics with seizures categorized according to international classification rules. We excluded: (i) patients with epileptic seizures due to an evolving disease, e.g., cerebral tumours, acute infections, metabolic or demyelinating maladies; (ii) epileptic alcoholics; (iii) patients with previous tonic-clonic epilepticus status; (iv) patients under psychiatric care and those taking narcotics; (v) long-term institutionalized patients; and (vi) pregnant women. Abiding by these criteria, we eliminated 31 patients, thereby permitting a more accurate assessment of 177 subjects who were divided into 3 groups: 106 chronic epileptic patients treated for seizures for 4 years or more, 28 de novo epileptics not treated or treated for less than 2 years, and 43 control subjects age-matched with the first 43 patients who entered the study.

\section{Clinical assessment}

The 134 epileptic (de novo and chronic) patients were divided according to radiological criteria into 3 groups: 55 with normal CT scans (group 1); 30 with both cerebral and CBS atrophy (group 2); and 49 with pure CBS atrophy (group 3).

Forty patients $(30 \%)$ had generalized tonic-clonic seizures, $72(54 \%)$ had partial seizures developing into secondary generalized seizures, $16(12 \%)$ had complex partial seizures, and the remaining $6(4 \%)$ had partial focal motor seizures. Of the 134 patients, 106 (79\%) had taken PHT either alone (37 subjects) or in association with phenobarbital (69 subjects) for 4 years or more, whereas 28 were either not treated or treated for less than 2 years. The length of the illness was calculated in months for each patient; the number of generalized and other seizures was recorded for the entire lifetime of each patient on the basis of clinical records from our hospital and from the Montreal Children's and Ste-Justine Hospitals. The total amount of PHT ingested during the patient's lifetime was calculated retrospectively (in grams) from the same records according to the method used by Bittencourt. ${ }^{14}$ The periods of PHT intoxication in the past were assessed on both biochemical grounds (PHT levels more than $20 \mathrm{ug} / \mathrm{ml}$ ) and clinical signs of acute cerebellar ataxia.

All patients underwent routine laboratory tests and serum PHT and phenobarbital determinations.

The neurological examination results were normal in all control subjects; clinical signs of chronic cerebellar ataxia were found in only 6 epileptics. All other patients were clinically asymptomatic.

\section{Radiological studies}

Radiological investigations, performed with an EMI-5005 CT scan, included $10-\mathrm{mm}$ high-resolution study sections of the posterior fossa.

Cerebral cortical atrophy was assessed according to the criteria of Huckman et $\mathrm{al}^{21}$ and Hahn and Kwan. ${ }^{22} \mathrm{CBS}$ atrophy was evaluated according to the parameters of Koller et al, ${ }^{23}$ namely, the cerebellar hemispheres were considered to be atrophied when folia were visible whereas vermian atrophy was deemed present upon finding two or more sulci in the midline. As suggested by these investigators, the superior cerebellar, cerebellopontine angle, quadrigeminal and lateral basal cisterns were subjectively evaluated along with the cisterna magna and fourth ventricle. As proposed by Koller et al, 23 two objective measurements were performed: the size of the fourth ventricle was expressed as a ratio of its lateral width divided by the maximum intermastoid distance, and the size of the brainstem was estimated as a ratio of the width of the pre-pontine cisterns divided by the distance between the posterior clinoid and fourth ventricle. The assessments were done independently by 2 observers (J.L.V. and E.A.) without knowledge of the clinical data retained by the neurologist (M.I.B.).

\section{Statistics}

The ANOVA test ${ }^{24}$ and the Dunnett test ${ }^{25}$ were used to compare the 3 groups. The Student's t-test ${ }^{26}$ was employed to compare groups 1 and 3 after the ANOVA test had ascertained that they were different.

\section{Results}

The first segment of this study was designed to evaluate the validity of our radiological assessment, i.e., the possible statistical correlation of the subjective assessments and the objective measurements in our 208 initial subjects (144 outpatient epileptics and 64 controls) (Table 1). In this part of our study, the variables were merely confined to the absence $(0)$, presence of mild to moderate (1), or moderate to severe (2) atrophy of the cerebellar hemispheres, brainstem and vermis. Both epileptics and controls were evaluated as a single group. From Table 1, it may be inferred, for example, that 141 subjects had no vermal atrophy, whereas 62 and 5 had mild and moderate to severe vermal atrophy, respectively.

In our series, the ratios of the fourth ventricle and brainstem increased statistically in proportion to atrophy of the vermis, the cerebellar hemispheres or brainstem. For example, 116 patients

Table 1: Correlation of Subjective Assessment and Objective Measurements of Posterior Fossa Atrophy in 208 Subjects

\begin{tabular}{llcc}
\hline \hline Groups & & $\begin{array}{c}\text { Fourth ventricle } \\
\text { ratio* }^{*}\end{array}$ & $\begin{array}{c}\text { Cistern/brainstem } \\
\text { ratio** }\end{array}$ \\
\hline & Subjective assessment & & \\
& ( ) number of patients & $\bar{x} \pm$ S.D. & $\bar{x} \pm$ S.D. \\
& Vermis (141) & $0.149 \pm 0.026$ & $0.209 \pm 0.038$ \\
Without & Cerebellar hemispheres (116) & $0.145 \pm 0.024$ & $0.202 \pm 0.035$ \\
atrophy & Brainstem (144) & $0.148 \pm 0.027$ & $0.204 \pm 0.034$ \\
1 & Vermis (62) & $0.159 \pm 0.032$ & $0.234 \pm 0.047$ \\
Mild atrophy & Cerebellar hemispheres (72) & $0.157 \pm 0.026$ & $0.237 \pm 0.042$ \\
& Brainstem (55) & $0.161 \pm 0.031$ & $0.245 \pm 0.039$ \\
2 & Vermis (5) & $0.222 \pm 0.079$ & $0.262 \pm 0.040$ \\
Moderate & Cerebellar hemispheres (20) & $0.191 \pm 0.057$ & $0.256 \pm 0.044$ \\
to severe & Brainstem (9) & $0.197 \pm 0.666$ & $0.301 \pm 0.039$ \\
atrophy & & & \\
\hline
\end{tabular}

*The size of the fourth ventricle is expressed as the ratio of its lateral width divided by the maximum intermastoid distance, whereas brainstem size is estimated as the ratio of the width of the pre-pontine cisterns divided by the distance between the posterior clinoid and fourth ventricle.

**ANOVA was used to assess all variables $(p<0.01$ ). The Dunnett test was employed for multiple comparisons between group 0 versus groups 1 and 2 , respectively $(\mathrm{p}<0.05)$. Orthogonal comparisons (Student's $\mathrm{t}$-contrast test) were carried out for the two ratios (separately for each location). The cistern/brainstem ratio between group 1 versus group 2 (cerebellar hemispheres) revealed a value of $p<0.05$ whereas the same comparison with vermal atrophy gave non-significant results. All other 10 orthogonal comparisons of both ratios among groups (group 0 versus group 1 plus 2 and group 1 versus group 2) revealed a value of $p<0.01$. 
Table 2: Cerebral and Posterior Fossa Atrophy in Epileptics $(n=134)$ and Controls $(n=34) *$

\begin{tabular}{|c|c|c|c|c|c|c|c|c|}
\hline \multirow[b]{2}{*}{ Groups } & \multirow[b]{2}{*}{ Number } & \multirow[b]{2}{*}{$\begin{array}{c}\text { Age } \\
(\text { yrs } \pm S D)\end{array}$} & \multirow[b]{2}{*}{$\begin{array}{l}\text { Cerebral } \\
\text { cortex }\end{array}$} & \multicolumn{2}{|c|}{ Atrophy in percentage of cases } & \multirow[b]{2}{*}{ Brainstem } & \multirow[b]{2}{*}{$\begin{array}{l}\text { Fourth Ventricle } \\
\text { ratio }(\vec{x} \pm S D)\end{array}$} & \multirow[b]{2}{*}{$\begin{array}{c}\text { Cistern/brainstem ratio } \\
(\ddot{\mathbf{x}} \pm \mathrm{SD})\end{array}$} \\
\hline & & & & Vermis & $\begin{array}{l}\text { Cerebellar } \\
\text { hemispheres }\end{array}$ & & & \\
\hline $\begin{array}{l}\text { I } \\
\text { Control subjects } \\
(8 \mathrm{M}, 35 \mathrm{~W})\end{array}$ & 43 & $40.2 \pm 14.5$ & $\begin{array}{l}14 \% \\
(0)\end{array}$ & $\begin{array}{l}12 \% \\
(0)\end{array}$ & $\begin{array}{l}12 \% \\
(0)\end{array}$ & $\begin{array}{l}2 \% \\
(0)\end{array}$ & $0.143 \pm 0.02$ & $0.204 \pm 0.03$ \\
\hline $\begin{array}{l}\text { De novo epileptics } \\
(12 \mathrm{M}, 16 \mathrm{~W})\end{array}$ & 28 & $40.7 \pm 14.9$ & $\begin{array}{l}7 \% \\
(0)\end{array}$ & $\begin{array}{l}14 \% \\
(0)\end{array}$ & $\begin{array}{l}14 \% \\
(0)\end{array}$ & $\begin{array}{l}11 \% \\
(0)\end{array}$ & $0.146 \pm 0.02$ & $0.207 \pm 0.03$ \\
\hline $\begin{array}{l}\text { Chronically-treated } \\
\text { epiteptics } \\
(49 \mathrm{M}, 57 \mathrm{~W})\end{array}$ & 106 & $42.7 \pm 14.6$ & $\begin{array}{l}26 \%+ \\
(3 \%)\end{array}$ & $\begin{array}{l}41 \% \# \\
(18 \%)\end{array}$ & $\begin{array}{l}57 \% \# \\
(8 \%)\end{array}$ & $42 \% \#$ & $0.157 \pm 0.03^{* *}$ & $0.225 \pm 0.04+$ \\
\hline
\end{tabular}

* Figures in parentheses give the percentage of cases with moderate to severe atrophy relative to the total number of patients from each group.

+ Different from the controls $(p<0.05)$

** Different from the controls $(\mathrm{p}<0.01)$

\# Different from the controls $(\mathrm{p}<0.001)$

without detectable cerebellar atrophy showed an average fourth ventricle ratio of 0.145 while 72 subjects with mild cerebellar atrophy presented a mean ratio of 0.157 , and 29 patients with moderately severe atrophy had a mean ratio of 0.191 .

Table 2 enumerates the frequency of cerebral and posterior fossa atrophy in epileptics and controls. It includes all categories of atrophy, i.e., both mild and moderately severe cases; the percentage of cases with moderate and severe atrophy is mentioned for each group. No significant statistical differences were evident between the 3 groups of patients in terms of age.

Among the 106 chronic epileptics, 68 (64\%) manifested atrophy of the vermis, cerebellar hemispheres or brainstem. Among the controls, vermal atrophy was found in 5 subjects (12\%) as compared with $4(14 \%)$ and $43(41 \%)$ in the de novo and chronic epileptics, respectively (Table 2 ). The same percentage of atrophy of the cerebellar hemispheres was noted in both control subjects and de novo epileptics, with a higher percentage being recorded in the chronic epileptics (60 patients, or $57 \%$ of cases). Concomitant brainstem atrophy was detected in 1 control subject $(2 \%)$, in $3(11 \%)$ de novo and $45(42 \%)$ chronic epileptics. Isolated atrophy of the brainstem was rare (3 patients).

There was a significantly higher incidence of CBS atrophy $(p<0.05)$ in chronic epileptics as compared to normal subjects and de novo epileptics; moderately severe cerebellar atrophy was present only in chronically-treated epileptics. There were however, no significant differences in the incidence and severity of cerebral, vermal and cerebellar hemisphere atrophy between de novo epileptics and normal controls.

Table 3 lists the means and standard deviations of variables possibly involved in the etiology of CBS atrophy in epileptic patients. Statistical comparisons revealed many significant differences. The patients with both cerebral and CBS atrophy (group 2) were significantly older and, like group 3, had suffered from epilepsy longer than group 1 (though there were some disparities between the Dunnett and Student's t-test results). The number of lifetime seizures did not correlate with the occurrence of either cerebral or CBS atrophy (Table 3). In a separate additional statistical analysis, there were no differences in the average seizure frequency (expressed as number per year) between the three study groups. In contrast, the lifetime intake of PHT was positively related to both cerebral and CBS atrophy. In group 2, cerebral atrophy seemed to be specifically related to age, in agreement with the data in the literature.

An analysis of individual cases showed that 29 patients had experienced acute periods of PHT intoxication. Among them, 7 (out of 55) had normal CT scans, 10 (out of 30) had cerebral and CBS atrophy, whereas the remaining 12 (out of 49) had CBS atrophy only. All other patients had pharmacological serum PHT levels; there was no significant difference in serum

Table 3: Possible Etiological Factors in Cerebral and Posterior Fossa Atrophy in Epileptic Patients

\begin{tabular}{|c|c|c|c|c|c|}
\hline $\begin{array}{l}\text { Group and number } \\
\text { of epileptics }\end{array}$ & $\begin{array}{c}\text { Age } \\
\text { (years) } \\
\bar{x} \pm S . D . \\
\text { (Range) }\end{array}$ & $\begin{array}{l}\text { Length of illness } \\
\text { (months) } \\
\bar{x} \pm \text { S.D. } \\
\text { (Range) }\end{array}$ & $\begin{array}{c}\text { Number of generalized } \\
\text { seizures during } \\
\text { lifetime } \\
\bar{x} \pm \text { S.D. } \\
\text { (Range) }\end{array}$ & $\begin{array}{l}\text { Number of other } \\
\text { seizures } \\
\mathrm{x} \pm \text { S.D. } \\
\text { (Range) }\end{array}$ & $\begin{array}{c}\text { Amount of PHT in grams } \\
\qquad \begin{array}{c}\bar{x} \pm S . D . \\
\text { (Range) }\end{array}\end{array}$ \\
\hline $\begin{array}{l}1 \\
\text { Normal CT scan } \\
55 \mathrm{Ss}(33 \mathrm{~W}, 22 \mathrm{M})\end{array}$ & $\begin{array}{l}35 \pm 12 \\
(18-71)\end{array}$ & $\begin{array}{l}116 \pm 118 \\
(1-384)\end{array}$ & $\begin{array}{l}24 \pm 43 \\
(0-200)\end{array}$ & $\begin{array}{l}177 \pm 633 \\
(0-4224)\end{array}$ & $\begin{array}{c}747 \pm 1073 \\
(0-4672)\end{array}$ \\
\hline $\begin{array}{l}2 \\
\text { Cerebral and posterior }\end{array}$ & $55 \pm 12$ & $256 \pm 206$ & $22 \pm 41$ & $544 \pm 1560$ & $1648 \pm 1203$ \\
\hline $\begin{array}{l}\text { fossa atrophy } \\
30 \mathrm{Ss}(16 \mathrm{~W}, 14 \mathrm{M})\end{array}$ & $(29-74)$ & $(1-768)$ & $(0-168)$ & $(0-8400)$ & $(0-4599)$ \\
\hline 3 & $40 \pm 13$ & $236 \pm 160$ & $41 \pm 75$ & $314 \pm 649$ & $1474 \pm 1227$ \\
\hline $\begin{array}{l}\text { brainstem atrophy } \\
49 \mathrm{Ss}(24 \mathrm{~W}, 25 \mathrm{M})\end{array}$ & $(20-74)$ & $(1-540)$ & $(0-397)$ & $(0-3000)$ & $(0-4380)$ \\
\hline
\end{tabular}

The ANOVA test revealed the following values for age $(p<0.01)$, length of illness $(p=0.004)$, number of generalized seizures $(p=6.55)$, number of other seizures $(p=0.356$ ) and total PHT intake $(p<0.027)$. The Dunnett test showed significant differences between groups 1 and 2 for age $(p<0.05)$, length of illness $(p<0.05)$ and total PHT intake $(p<0.05)$; there were no significant differences between the number of generalized and other seizures. In comparing groups 1 and 3, all $p$ values were non-significant except for total PHT intake $(p<0.05)$. The Student's t-test (group 1 versus group 3 only) showed significant differences only for the length of illness $(p<0.02)$ and total PHT intake $(p=0.004)$. 
PHT between the groups. Chi-square analysis indicated no significant relationship between the incidence of intoxication and a specific radiologically-defined group.

Among the 6 epileptics with chronic cerebellar ataxia, 4 had moderately severe whereas 2 had mild cerebellar atrophy. Three of these patients also had cerebral atrophy. The mean age of this group was $54.83 \pm 16.76$ years $(\bar{x} \pm$ S.D. $)$ (range: $20-70$ years); the length of the illness was $373.33 \pm 256.61$ (range 60-768) months; the total number of generalized seizures was $13.33 \pm 9.34$ (range: 1-22), whereas the total amount of PHT intake was 2055.5 \pm 1537.77 (range: 219-4380) grams.

Four of these subjects also underwent periods of PHT intoxication in the past. Despite the small number of cases, it may be concluded that chronic cerebellar ataxia follows long-lasting PHT treatment, usually in association with past periods of drug intoxication.

\section{Discussion AND CONCLusion}

\section{Radiologic findings}

From the first segment of our study (Table 1), it can be concluded that there was an excellent statistical relationship between the subjective assessment of CBS atrophy on the one hand and the values of the objective neuroradiological parameters (namely, measurement of fourth ventricle and brainstem ratios) on the other.

The second part of our study differed from the previous large series reported in the literature on cerebellar atrophy in epileptics ${ }^{12-14}$ because we separated our subjects into 3 categories, i.e., we divided the epileptics into de novo and chronic patients, and excluded all institutionalized or psychiatric epileptic patients.

In an earlier survey, Ballenger et al ${ }^{19}$ examined the CT scans of 70 patients with seizures and 48 subjects with headaches. They found no evidence that either PHT or epilepsy caused cerebellar atrophy. The following facts could explain the discrepancy between our results and those of Ballenger et al:19 1) they included chronically-treated epileptics, i.e., patients who were taking PHT for years, in the same group with non-treated epileptics and those on PHT therapy for some months; 2) in the control group, they included 3 patients with cerebellar conditions of various etiologies as well as 2 patients receiving PHT for unknown reasons; 3) 14 of their patients who were taking PHT for seizures had clinical signs of cerebellar dysfunction; 4) finally, they used only subjective radiological assessments. That CBS atrophy could also be encountered in normal subjects, as stated by Ballenger et al, ${ }^{19}$ was, however, confirmed in our study.

From our investigations, the conclusion drawn is that, despite occasional atrophy of the vermis, cerebellar hemispheres and brainstem in both control subjects and de novo epileptics, its incidence and severity are statistically more pronounced in chronic PHT- or PHT+ phenobarbital-treated epileptics.

\section{Etiology of cerebellar atrophy}

Although many cases of permanent ataxia have been reported following large doses of PHT or prolonged treatment with this drug, ${ }^{16}$ very few studies with large series of patients have established its possible etiological role in inducing CBS atrophy. Such investigations have usually been undertaken on institutionalized epileptics with mental disorders and have yielded inconsistent results. ${ }^{12.14} \mathrm{We}$ have, however, confirmed Bittencourt's observations, ${ }^{14}$ that a strong correlation exists between combined cerebral and CBS atrophy and age.

The controversy over PHT as an etiological factor in CBS atrophy among chronic epileptics is ongoing. Because of the inconsistency of experimental data on this point, and also because cerebellar atrophy in epileptics was well-documented before PHT became a treatment for epilepsy, 17 hypoxia due to frequent generalized seizures has been suspected as the cause of CBS atrophy. ${ }^{27}$ Indeed, some clinical neuropathological 28 and experimental studies ${ }^{29}$ have revealed that epilepsy and, more specifically, status epilepticus can induce hippocampal and cerebellar lesions. To avoid such a possibility, patients with status epilepticus were excluded from the present investigation.

Our three most significant findings were that: (i) in a large series of patients, the number of epileptic seizures was not statistically a major determinant of CBS atrophy; (ii) the main etiological agent in CBS atrophy was PHT treatment, and more precisely, the total lifetime intake of PHT; and (iii) the length of the illness was another factor which could be considered as a determinant of CBS atrophy, although it was, of course, usually related to the duration of PHT therapy.

The past controversy between the advocates of the hypoxiametabolic theory versus those of the PHT hypothesis arises from the fact that recent and de novo epileptics (as well as some normal subjects) display CBS atrophy, but chronically-treated epileptics have a higher incidence and severity of atrophy than the other two groups. More recently, Dam ${ }^{15}$ suggested that cerebellar lesions in epileptics are caused by "basic biochemical derangements which are closely connected to the epileptic hyperactivity in the brain and not necessarily by hypoxia in connection with generalized tonic-clonic seizures".

In our opinion, this working hypothesis, which tries to reconcile two opposing view points, was not confirmed by our study because: (i) the number of generalized seizures was not statistically related to the occurrence of CBS atrophy; and (ii) the theory could not explain the cerebellar ataxia evident after PHT intoxication in individual cases, as demonstrated in this as well as in previous studies. ${ }^{16}$ To quote Reynolds: ${ }^{30}$ "The fact that you are unlikely to find a correlation between PHT intoxication and cerebellar atrophy would not, in my view, invalidate individual clinical observations". We agree with, and confirmed, this point of view. The theory would also explain with some difficulty, the absence of hypoxia-induced tissue alterations in PHT-treated epileptics. ${ }^{11}$

In conclusion, we believe that PHT is the main cause of CBS atrophy in chronic epileptics, since it was correlated with the length of PHT treatment. A possible role of seizures in individual cases cannot, however, be excluded.

\section{ACKNOWLEDGEMENTS}

This work was supported by a grant from the Bernard-Dubois Fund (to M.I.B.). Ezzedine Attig was recipient of a fellowship from the Jeanne Mance Foundation.

The authors thank Mr. Ovid DaSilva of Better Communications, Inc., for editing this manuscript. 


\section{REFERENCES}

1. Hofmann WW. Cerebellar lesions after parenteral dilantin administration. Neurology 1958; 8: 210-14.

2. Utterback RA. Parenchymatous cerebellar degeneration complicating diphenylhydantoin therapy. Arch Neurol Psychiatry 1958; 80: $180-1$.

3. Roger J, Soulayrol R. A propos des accidents neurologiques du traitement de l'épilepsie par les hydantoines. Rev Neurol (Paris) 1959; 100: 783-85.

4. Haberland C. Cerebellar degeneration with clinical manifestations in chronic epileptic patients. Psychiatr Neurol (Basel) 1962; 143: $29-44$.

5. Kokenge R, Kutt H, McDowell F. Neurological sequelae following Dilantin overdose in a patient and in experimental animals. Neurology (Minneap) 1965; 15: 823-9.

6. Selhorst JB, Kaufman B, Horwitz SJ. Diphenylhydantoin-induced cerebellar degeneration. Arch Neurol 1972; 27: 453-5.

7. Ghatak NR, Santoso RA, McKinney WM. Cerebellar degeneration following long-term phenytoin therapy. Neurology (Minneap) 1976; 26: 818-20.

8. Salcman $M$, Defendini $R$, Correll J, et al. Neuropathological changes in cerebellar biopsies of epileptic patients. Ann Neurol 1978; 3: 10-19.

9. McLain LW, Martin JT, Allen JH. Cerebellar degeneration due to chronic phenytoin therapy. Ann Neurol 1980; 7: 18-23.

10. Koller WC, Glatt SL, Fox JH. Phenytoin-induced cerebellar degeneration. Ann Neurol 1980; 8: 203-4.

11. Breiden-Arends C, Gullotta F. Diphenylhydantoin, Epilepsie, Kleinhirnatrophie-Histologische und elektronenmikroskopische Untersuchugen. Fortschr Neurol Psychiatr 1981; 49: 406-14.

12. livainen $M$, Viukari $M$, Helle E-P. Cerebellar atrophy in phenytointreated mentally retarded epileptics. Epilepsia 1977; 18: 375-85.

13. Tsukamoto $\mathrm{Y}$, Kondo K, Yoshiota M. Antiepileptic drugs and cerebellar atrophy. Acta Neurol Scand (Suppl. 79) 1980; 62: 89.

14. Bittencourt PRM. Cerebral and cerebellar atrophy in patients with severe epilepsy: a preliminary report. In: Oxley J, Janz D, Meinardi H, eds. Antiepileptic Therapy: Chronic Toxicity of Antiepileptic Drugs, New York: Raven Press, 1983: 237-45.

15. Dam M. Chronic toxicity of antiepileptic drugs with respect to cerebellar and motor function. In: Oxley J. Janz, D, Meinardi H, eds. Chronic Toxicity of Antiepileptic Drugs, New York: Raven Press, 1983: 223-28.
16. Botez MI, Gravel J. Attig E, et al. Reversible chronic cerebellar ataxia following phenytoin intoxication. The possible role of the cerebellum in cognitive thought. Neurology (Cleveland) 1985: 35: $1152-57$.

17. Spielmeyer W. Uber einige Beziehungen zwischen Ganglienzelleveranderungen und gliosen Erscheinungen, besonders am Kleinhirn. Z ges Neurol Psychiatr 1920; 54: 1-38.

18. Merritt HH, Putnam TJ. Sodium diphenylhydantoinate in the treatment of convulsive disorders. J Am Med Assoc 1938: 111: 1068-73.

19. Ballenger CE, Lucke JF, King DW, et al. Cerebellar atrophy in epilepsy and headache: lack of relationship to phenytoin. Neurology (NY) 1982; 32: 910-12.

20. Mattson RH, Cramer JA, Escueta AVD, et al. A design for the prospective evaluation of the efficacy and toxicity of antiepileptic drugs in adults. Neurology (Cleveland) 1983; 33 (Suppl. 1): 14-25.

21. Huckman MS, Fox JH, Topel JL. The validity of criteria for the evaluation of cerebral atrophy by computed tomography. Radiology 1975; 116: 85-92.

22. Hahn FJY, Kwan R. Frontal ventricular dimensions on normal computed tomography. Am J Roentgenol 1976; 126: 593-6.

23. Koller WC, Glatt SL, Perlik S, et al. Cerebellar atrophy demonstrated by computed tomography. Neurology (NY) 1981; 31: 405-12.

24. Kirk RE. Experimental design: procedures for the Behavioral Sciences. Wadsworth, Belmont, 1968.

25. Winer BJ. Statistical principles in experimental design. McGrawHill, New York, 1971.

26 Ferguson GA. Statistical analysis in psychology and education. New York: McGraw-Hill, 1971.

27. Dam M. Number of Purkinje cells in patients with grand mal epilepsy treated with diphenylhydantoin. Epilepsia 1970; 11: 313-320.

28. Marguerison JH, Corsellis JAN. Epilepsy and the temporal lobes. Brain 1966; 89: 499-533.

29. Meldrum BS, Horton RW, Brierley JB. Epileptic brain damage in adolescent baboons following seizures induced by allyglycine. Brain 1974; 97: 407-18.

30. Reynolds EH. Discussion: motor and cerebellar disorders. In: Oxley J, Janz D, Meinardi H, eds., Chronic Toxicity of Antiepileptic Drugs, New York: Raven Press, 1983: 249. 